\title{
ONLINE COURSES AND THEIR IMPACT ON FORMAL EDUCATION AND EDUCATION OF ADULTS
}

\author{
Srđan Trajković1, \\ Dragan Cvetković2, \\ Duško Radaković1, \\ Dominik Brkić1
}

\author{
${ }^{1}$ Visoka škola strukovnih studija \\ Beogradska politehnika, \\ Belgrade, Serbia \\ ${ }^{2}$ School of Informatics and Computing, \\ Singidunum University, \\ Belgrade, Serbia
}

\begin{abstract}
:
In this paper we will present basic definitions of online courses. The impact of such courses on formal education will also be presented. One of the goals of this paper is to define online courses as a possibility for adult education and lifelong learning as such. The importance of creating a national platform for online education will be pointed out. A proposal defining the platform and communication will also be presented in this paper.
\end{abstract}

Keywords:

online course, online education, adult education, lifelong learning.

\section{INTRODUCTION}

We are aware that the obsolescence of knowledge is very short nowadays. In some technologies it is even shorter than a year. Therefore, being intellectuals we have to improve our knowledge regularly.

New information and communication technologies offer us a way which can be available to everyone.

The development of distance learning allows us to create courses in the web-based environment that can significantly improve our knowledge.

A lot of high schools and universities, especially in developed countries, implement distance learning in their systems. Developed countries have also adopted a strategy for distance learning.

We will present National documentation which is developed and adopted in Serbia regarding the development of learning and adult education.

Our goal is also to demonstrate that lifelong learning is not only intended for older people.

\section{E-LEARNING}

\section{Correspondence:}

Srđan Trajković

e-mail:

strajkovic@politehnika.edu.rs
Any kind of teaching in which we use ICT can be catogorized as elearning. Almost all universities and faculties have implemented some kind of distance learning system trying to provide better student- professor communication and overcome cost difficulties for campus students. 
There are a lot of different ways of transferring knowledge nowadays, from face to face classic courses to various e-learning platforms. New IC technology allows us to have a new approach in learning. In developed countries like America and in all European countries e-learning in some way dominates as learning practice.

We are witnesses that in these countries even a K12, high and particularly higher education are dependent on computer and communication technologies.

Various types of e-learning systems are implemented. We can differentiate these ways of implementation:

- Classroom course - most of the course is implemented in the classroom using computer technologies as a teaching tool where students can try virtual laboratories, simulations etc.

- Synchronous distributed course- these courses are based on web technologies and intended to improve classic lecturing. They are often based on video conferencing.

- Web enhanced course - in this type of course students must complete the defined task using the Internet technologies.

- Blended classroom course - these kinds of courses assume that some part of face to face lectures will be replaced by online activities.

- Blended online course - these courses are similar to the previous ones but the online activities are used in much bigger percentage.

- Online course - all required activities are done online. There are no face to face lectures.

The most common learning systems are blended courses, but better schools with good technological equipment and educated staff organize online courses.

\section{ONLINE COURSES}

According to a previous definition online courses are based on online activities, and they allow a participant to choose the time and the place, i.e. when and where he or she wants to participate in a course. This is very significant for participants and for organizers of courses.

If the organizer of a course is a school or university, during this course it can use its staff or material resources (classrooms) for other activities (another face to face classes). This fact is very attractive to every school. Good environment, good technical opportunities and good quality of staff are evidently an advantage. Of course, the strategy of the society also plays an important role.
Highly defined societies take more advantages from new technologies.

Such courses allow students to organize their time in a better and more efficient way. Students can choose when and where to listen to a lecture (at home, in a dorm, in a library or maybe in a coffee shop if they want). This is a great feature because the system of campus does not primarily mean living and studying any more. You can study from home, from a different town, even from a different country. The number of these students can rise and can improve the material and technical level of schools and universities. The tuition for these students is significantly smaller than for classical students. We have also noticed that a lot of higher schools and universities are opening e-learning online courses to support adult population.

These courses can even be attended by students who are not formally enrolled in that school. In fact a very large number of social and educational organizations create online courses in order to improve people's way of living. They teach foreign languages, art, social activities, how to use social networks in communication, elementary software etc. This is the best way of implementing online courses for lifelong learning.

\section{COURSE ORGANISATION}

When a person or an organization decides to open an online course or courses, they have to make several serious decisions.

First they have to define the theme and the object of the course and then to decide which goals are to be achieved.

Of course, marketing needs to be on a high level in order to make participants interested in such a course.

The way of communication and transfer of information must be well defined. A protocol of security has to be well designed, too.

Learning management system must be chosen in a proper way.

Some organizers choose the existing platforms to present and teach a defined course.

\section{LEARNING MANAGEMET SYSTEMS (LMS)}

In educational environment there are several well known and developed learning management systems for online courses. Some of them are commercial but some are open source. What is Learning management system? 
It is a software which has a goal to present documentation, administrative communication, track the presence of participants in their sessions, evaluate scores and create a report of realized activities. There is a very large number of Learning management systems.

In our environment MOODLE and CANVAS are most popular but in global educational market BLACKBOARD has more participants. Adobe activate prime is the most popular LMS in America. Almost all their administration use this LMS.

The main difference is that Blackboard, Moodle and Canvas are often used even in formal education at universities and high schools.

Moodle platform is most frequently implemented in formal education in Serbia. For informal learning, organizers often offer courses mounted on individual web sites. There are a lot of sites organized by known universities that provide courses or a bundle of courses for informal learning.

Coursera, Edx, Udacity are the most known sites for such purpose.

Our research shows that the defined platform (site) for online courses and education of national interest does not exist in Serbia.

There are a lot of individual sites with online courses but there is not the defined global strategy.

\section{LIFELONG LEARNING IN SERBIA}

During the course of this work we were analysing online courses as instruments of formal learning. But the application of these courses can be much more useful.

Online courses can be the basics of informal learning in any way.

All national strategies incuding Serbian include the prediction of informal and lifelong learning.

In Serbia, national strategy of adult education was adopted in 2005 but the law regarding adult education was adopted in 2013.

Europe has a strategy of lifelong learning which was adopted in 1977. According to the research results over 15 percent of adults older than 65 use some kind of course for personal education. When our country is concerned, there is no credible information about the number of participants.

A period of knowledge obsolescence is nowadays less than 3 years ago. In some technologies it is even shorter. So everyone who has gained formal education needs to participate in informal education or lifelong learning.
When we say lifelong learning we think of adult education but in a way which is different from their formal education.

Based on our experience, lifelong learning could be any learning different from formal education that a person can get, regarding his /her age. For example, if you are a metal worker and you learn something about bookeeping it can also be categorized as lifelong learning.

The research indicates that if courses are concetrated on one or few sites, the potential participants will find the course with the subject of their interest more easily.

After our research we suggest that the state should make an effort in creating LMS and the site for adult education. In addition, the education through this platform should be free of charge and massive. We do not think that the age boundary has to be high. Middle aged people should be involved in this kind of education as well. They need basic computer literacy so that they could join any course they are interested in. The level of knowledge and work qualification should be better, which is good for all employers and the country in general.

\section{BELGRADE POLYTECHNIC EXPERIENCE}

In Belgrade polytechnic school (Politehnika) there were significant efforts in implementing E-learning system. We started with some digital publications in addition to our classical lessons. Students reacted very positively to this action.

The next step was implementing Moodle platform in several school subjects. Professors created lectures, tests, colloquiums etc. The achieved results were expected but there was no significant improvement in students' success. Basically, students had the same level of success as students who were in a face to face program. But after some analysis we were satisfied because some material savings were made and we also gained education for our teaching staff.

We continued using steps to improve e-learning. The implementation of video lectures into our site made a difference in increased throughput on subjects. Throughput has risen for about $15 \%$.

In the last two years we have implemented g-mail server for all our students and we have also implemented Google Education learning system.

Trails system is made on courses which cover computer science. The result is satisfactory. We still have small proplems in implementation but overall, everything is working. 
We use G-Drive, G-Docs, Google Classroom, Google Forms and other google applications plus BigBlueButton as software for online streaming.

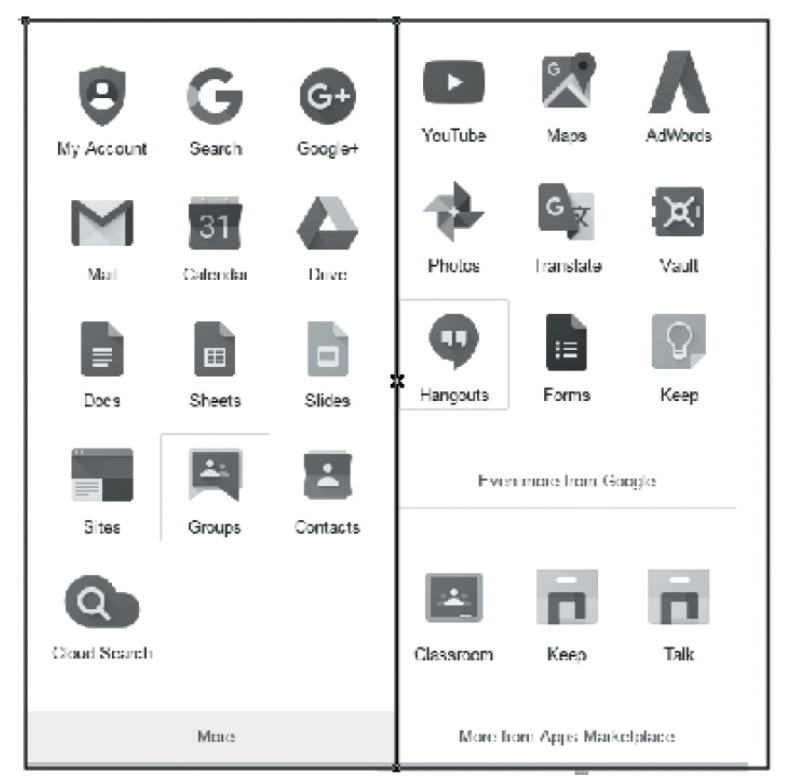

Fig. 1. Google Education applications

The group of students that we were monitoring in this project had to complete all assignments online. For homework assignment we used Google classroom. We created lessons. In these lessons we implemented all necessary materials (documents, slides, video etc..., and we also implemented a homework assigment).

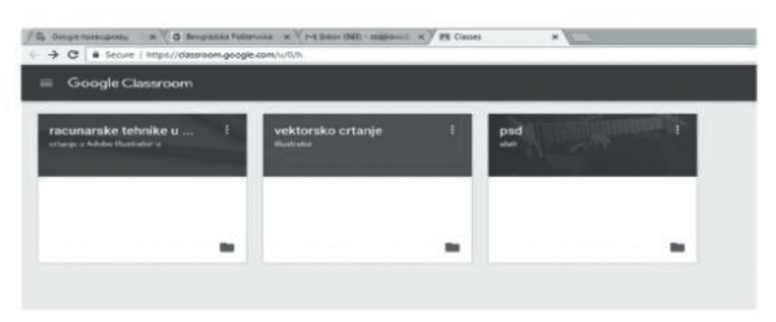

Fig. 2. Lessons in Google Classrom

The monitored group was chosen randomly. The achieved results were good.

The problems we encountered were technical. The speed of Internet connection was generally low, especially our upload of data. As a solution to this problem we created small groups of students that participated at the same time. We also changed the speed package of the Internet. We have noticed that education of teaching staff is needed if we want to improve this kind of education.
As a member of group of schools we participate in the European project of Waste management and as a part of this project, whose goal is to improve people's awareness of the significance of waste management, we are creating an online course for anybody who is interested in that matter. This course will be launched on the Internet in the second half of this year. The expectations are high.

We use Google Classroom as a primary software and we will show several key steps how Classroom works.

First you create a class.

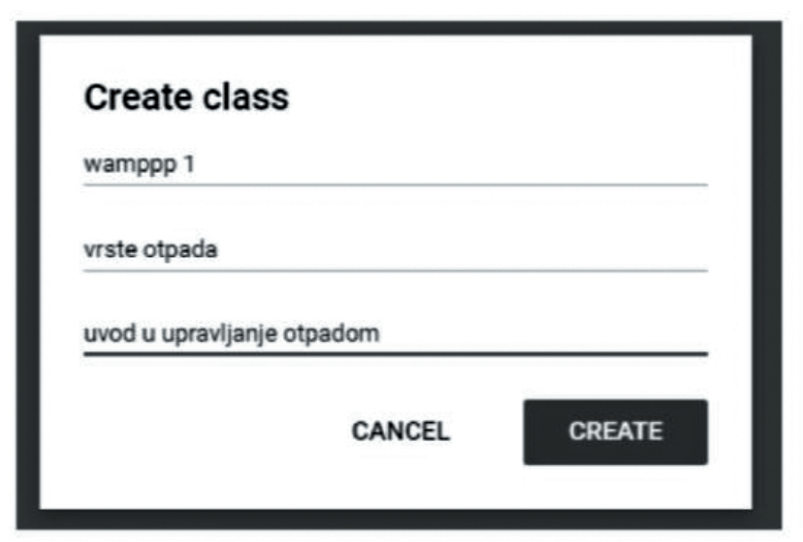

Fig. 3. Screen of creating class

Then a professor enters a class to insert a post and assigments to students

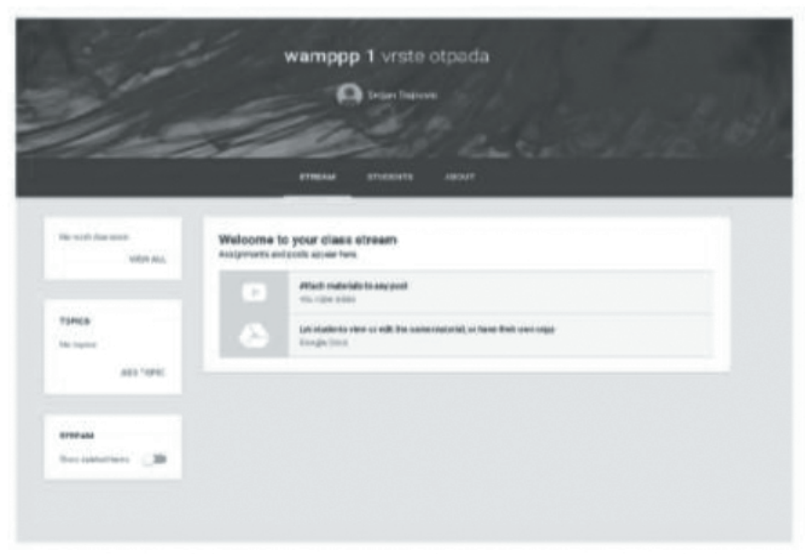

Fig. 4. Screen of created class

For the assigment of tasks and definition of post we use the menu on the right side of the screen. 


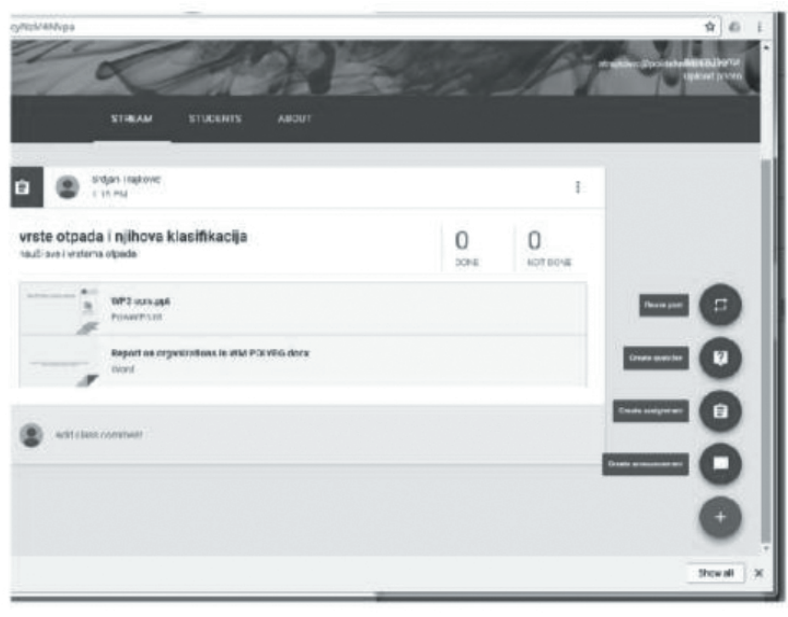

Fig. 5. Menu for adding assignments, questions, posts

When everything is defined the invitation of students follows.

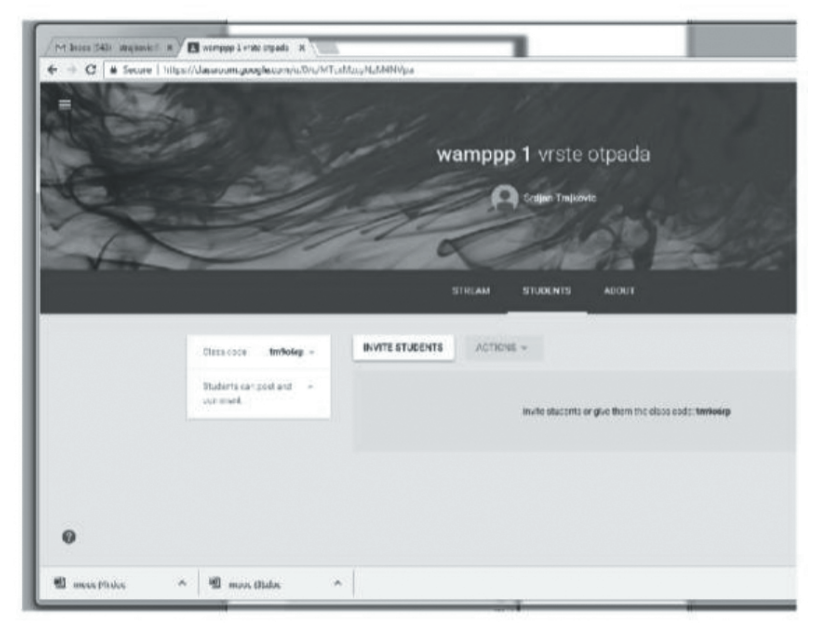

Fig. 6. Invitation of student screen

After this step students get a message with a link to the class. Students can download all materials and when they finish the assignment they answer the questions. They get grades and after that they pass to another class. It is not necessary that students submit their homework in the order of classes.

This course will be one of many courses which we plan to offer to open population of users, not only to students. In that way we plan to engage schools in the program of lifelong learning.

\section{CONCLUSION}

This paper shows results of research of online courses and their possibilities in formal and informal education. It has just scratched the surface of this subject.

The prospects of using online courses are very promising and everyone should think how to engage in such a thing in the future.

Platform of informal education including lifelong learning based on national interest will be a great step for all the people who want to be active even in the old age.

We hope that such idea will find its way to a state government and will be implemented in the next national strategy.

\section{REFERENCES}

[1] Marjorie Vai, Kristen Sosulski, "Essentials of Online Course Design: A Standards-Based Guide", Routledge; October 25, 2015

[2] Joan Thormann, Isa Kaftal Zimmerman, "The Complete Step-by-Step Guide to Designing and Teaching Online Courses", Teachers College Press (March 16, 2012)

[3] Adam Witty, "Log On and Learn: How To Quickly and Easily Create Online Courses That Expand Your Brand, Cultivate Customers, and Make You Money While You Sleep", Advantage Media Group (April 1, 2013)

[4] Vladimir Raykov, "How To Build Your Successful Online Teaching Business", February 25, 2016

[5] Qiyun Wang, "A generic model for guiding the integration of ICT into teaching and learning", Journal Innovations in Education and Teaching International, Volume 45, 2008 - Issue 4

[6] http://dodjohvidehnaucih.eu/celozivotno-ucenje/ nacionalna-dokumenta/

[7] https://elearningindustry.com/the-20-best-learning-management-systems

[8] https://onlinelearningconsortium.org/updated-elearning-definitions-2/

[9] http://www.idea.org/blog/2012/01/11/what-is-anonline-course/ 